\title{
A STUDY ON ANALYSIS AND DESIGN OF METADATA MODEL FOR INTELLIGENT TUTORING SYSTEM
}

\author{
Jin-Cheul Jang, Korea Advanced Institute of Science and Technology, KOREA, jcjang@kaist.ac.kr \\ Seong-Yong Hong, Korea Advanced Institute of Science and Technology, KOREA, gosyhong@kaist.ac.kr \\ Yong-Hyun Hwang, University of California Irvine, USA, yonghyuh@uci.edu
}

\begin{abstract}
Emerging social network services along with increased user participation necessitate diverse changes in e-learning systems. To support the changes effectively, the standardization of metadata plays a key role in that metadata is the agreement for interoperability among different and diverse systems. Up to now, lots of efforts have been paid for the standardization by domestic and international organizations. However, adopting the diverse changes into the design of e-learning metadata is still challenging. To mitigate the issue, this paper a) proposes a methodology for analysis and modeling of e-learning metadata, b) elicits the design requirements of the elements required in future e-learning systems, using the metadata standard KEM 3.0, and c) presents the three-layer model to classify the requirements by the importance of metadata elements per Kano Model. Based on a), b), and c), it is expected that an intelligent $e$ learning system is to be developed while effectively supporting diverse changes, which, in turn, would influence the development of an international standard in the future.
\end{abstract}

Keywords: e-Learning Metadata, Intelligent Tutoring System, Korea Education Metadata, Metadata Model

\section{INTRODUCTION}

Recent Information Technology has been changed through mobile, multi-device environment, social networks, semantic web, web 2.0 and the phenomenon of collective intelligence [1, 2]. Especially, emerging smart phones and the development of social network services make users distributing the information anytime and anywhere. According to the research by Forrester Research in 2009, the result of the research was shown that the user participation is steadily changed more actively through the evolution of information technology environment [3]. By the research, the users who read the articles or reviews in the online community had been increased from $48 \%$ in 2007 to $73 \%$ in 2009. Moreover, the users who create the contents had increased from $18 \%$ in 2007 to $24 \%$ in 2009 , and the users who post reviews or reply the comments had also increased from 25\% in 2007 to 37\% in 2009. However, inactive users who do not perform any activities in online communities had largely decreased from $44 \%$ in 2007 to $18 \%$ in 2009. In short, by the exchanging the technology environment, users' participation in online communities has been changed more actively [4]. Meanwhile, the e-Learning area, which provides the learning environment based on the computer systems to the learners, has been developed in the decades. In addition, web-based e-Learning systems, which can enhance the interactions between learners, and pursuit the open and distributed learning spaces, have been utilized in the use with support tools for the general education, for the lifelong education, and for the open course ware tools [5]. In the recent research cases, there are several researches that new services or systems, such as social network services and collaborative recommendation systems, can be affected to the improvement of users' learning environment. For example, Junco et al. provided an experimental evidence that Twitter can be used as an educational tool to help engage students and to mobilize faculty into a more active and participatory role [6], and Manouselis et al. conducted the research results that the development of such systems should be taking place considering the particularities of the actual communities that are to be served [7]. Similarly, the direction of changing the information technology environment is related to the changes of e-Learning environment, and it is predicted that the appearance of new devices such as tablet PC or IPTV (Internet Protocol TV) make a positive effect to the learners.

In this paper, we will propose new e-Learning metadata model to support advanced learning environment through the evolution of users' activity in the online community. In addition, we will deeply consider the element of multi-device education environment and social computing environment that supports user participation. Therefore, we develop this research with the following steps. Firstly, we will explain the related research for e-learning metadata standards and the trends for using the metadata standards. Next, we will elicit the requirements for designing the new metadata model 
with 3-Layers model, and design the metadata model with the requirements. Finally, we conclude with some contributions about this research.

\section{RELATED WORK}

Metadata is often defined as 'data about data', or defined more concretely as 'information about an object, be it physical or digital'. The purpose of metadata is 'to facilitate search, evaluation, acquisition, and use' of resources [8]. Metadata is always defined as authorized organization (e.g. the Government), but sometimes it is standardized by the popularity of uses. The most useful advantage of using metadata is interoperability. Interoperability defines as enabling information that originates in one context to be used in another in ways that are as highly automated as possible. Standards can be defined as "documented agreements containing technical specifications or other precise criteria to be used consistently as rules, guidelines, or definitions of characteristics, to ensure that materials, products, processes and services are fit for their purpose”. In the context of e-learning environment, standards are generally developed to be used in systems design and implementation for the purposes of ensuring interoperability, portability and reusability [9]. In 2000s, the standardization of e-Learning metadata was driven by the worldwide organizations and groups. There are international e-Learning metadata such as SCORM (Sharable Content Object Reference Model), IMS Common Cartridge, and LOM (Learning Object Metadata), and there is one Korean domestic e-Learning metadata called KEM (Korea Education Metadata) 3.0. Advanced Distributed Learning (ADL), one of the American committee for next distributed learning system, defined SCORM for the runtime environment and contents model about learning objects in the web based eLearning systems. IEEE LTSC (Learning Technology Standards Committee), another international e-Learning standardization organization, presented LOM for defining the learning objects. LOM consists of nine categorizations: General, Life Cycle, Meta-Metadata, Technical, Educational, Rights, Relation, Annotation, Classification, and each categorization have several hierarchical elements [10]. Moreover, there is KEM 3.0, a domestic standardized e-Learning data specification in Korea developed by Ministry of Education and Korea Education and Research Information Service Institute (KERIS). Different from other countries which standardization is supported by private organization, standardization in Korea is driven by Korean Government. Nowadays, KEM 3.0 is used in both K-12 education and advanced education in the university. It is based on LOM specification, and nine categorizations of KEM 3.0 are same as those of LOM; however, some elements of KEM 3.0, which are for conditions in Korean education, are different from LOM [11].

\section{ANALYSIS AND DESIGN OF E-LEARNING METADATA MODEL}

In this part, we find new e-Learning metadata design requirements for adapting advanced information technology environment (e.g. SNS and multi-device environment). We analyze the requirements based on KEM 3.0 metadata and want to expand the model with adding changing technological environments. According to the research about eLearning metadata management which objects were workers for managing the data in 10 universities in 2008, general, life cycle, technical, relation, classification categories in KEM were essentially used in 6 universities. Meta-metadata category was essentially used in 3 universities, while educational, rights, annotations categories were used in less than 2 universities. However, the workers recognized that the rights category will be important in the future because the importance of rights management about digital resources will be essential. Moreover, the case of educational category, because the object of former research was limited to the university, defining educational category was unnecessary [12]. Based on this survey, we classify three importance level of KEM 3.0 metadata as Table 1.

Table 1. Classification of KEM 3.0 Metadata Importance based on e-Learning metadata workers

\begin{tabular}{|l|l|}
\hline Importance & Categories \\
\hline High & General \\
& Life Cycle \\
& Technical \\
& Relation \\
\hline Medium & Classification \\
& Meta-metadata \\
\hline Low & Educational \\
\hline
\end{tabular}


Nowadays, it is needed to improve the metadata structure in order to be comprehensive and concise for various participators, because learning contents and users who join to the e-Learning are increased. First, in KEM 3.0 model, the identifier element is existed in general, meta-metadata, relation category with the same name, and the contribute element is also existed in life style, meta-metadata category with the same name. These situations can provide unified condition to the metadata users, but they can cause confused situation for managing the data. Therefore, it is needed to name separately such as 'General Identifier' in each category. Next, the name element under the technical category represents the required technology to describe more details about the required technology. It means that the name element is used for representing the operating system in order to implement the metadata technically, but the element name 'name' cannot cover this concept. Therefore, it is needed to change the name concretely such as 'Operating Systems Name'. Last, interactivity level, semantic density, and difficulty elements in educational category can be entered five levels of educational resources evaluated by system managers. In the case of intelligent tutoring system, learners or general users can determine the level of documents by using the rate or comments, so these elements should categorized by evaluators: system managers, providers, and users.

As mentioned, IT environment changes to support user participation and to make a social network with the technology, the current user can generate the contents more actively than the past user. For example, the users can share their opinions through the blog, or social network services. That is, it is needed to apply the open rights systems, e.g. CCL (Creative Commons License), for the online environment where various users joined such as the phenomenon of collective intelligence. The objective of CCL is to develop, support, and steward legal and technical infrastructure that maximizes digital creativity, sharing, and innovation. Different from the copyright which is a set of exclusive rights granted to the author or creator of an original work, Creative Commons can permit for other users to use freely by the condition which determined by the creator or author in the legal environment. CCL can guarantee both free utilization of contents and copyright protection from illegal uses. CCL is standardized by W3C (World Wide Web Consortium) [13]. Meanwhile, it is needed to manage the information about multi-device IT environment such as IPTV and tablet PC. For instance, the channel name, ID, and payment method are contained in the new metadata.

Pedagogical model and e-Learning based tutoring methods are developed with various forms. With changing the pedagogical learning models as Self-leading study, project-based learning, and problem-based learning, the e-Learning models are also changed like game-based learning (G-Learning), robot-based learning (R-Learning), and IPTV-based learning (T-learning). In the recent time, new pedagogical approaches such as collective intelligence based learning, computer-supported collaborative learning are appeared, so consideration for user participation in the education is heavily important.

In KEM 3.0 model, elements of interactivity type and levels between learners, pedagogical methods can be defined in the educational category. For the supplementation of these elements, it is needed to design new metadata in order to apply the requirements for various education environments.

In the field of marketing management, Kano et al. (1984) developed a model to categorize the attributes of a product or service based on how well they are able to satisfy customer needs. There are three main categories of Kano concepts: the must-be or basic needs, the one-dimensional or performance needs, and the attractive or excitement needs. First, the must-be requirement is a situation that users become dissatisfied when performance of the product attribute is low. However, user satisfaction does not rise above neutral even with a high performance of the product attribute. Next, the one-dimensional requirement is a situation that user satisfaction is a linear function of the performance of the product attribute. High attribute performance leads to high customer satisfaction. Last, the attractive requirement is a situation that user satisfaction increases super-linearly with increasing attribute performance. There is, however, not a corresponding decrease in user satisfaction with a decrease in attribute performance [14, 15].

In this research, we apply Kano's theory into the design of metadata in Figure 1. The product attribute in the theory will be the performance of each metadata attribute, and the user satisfaction will be importance of metadata from the metadata workers. 
Volume XII, No. 2, pp. 74-79, 2011

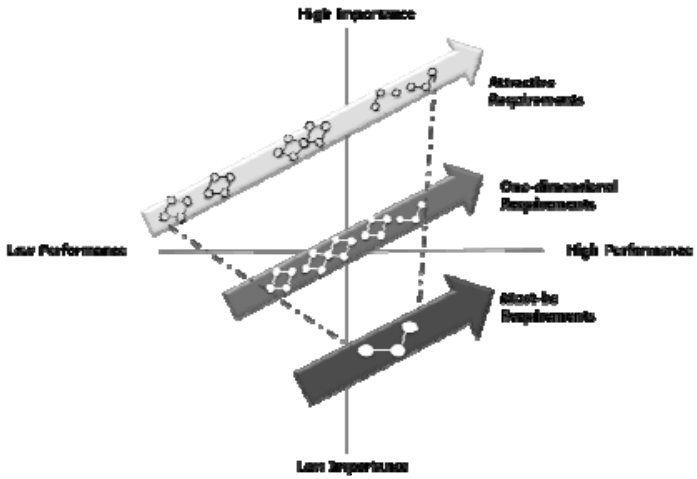

Figure 1. 3-Layer Metadata Model

By the importance of the e-Learning metadata from Figure 1, five categories, such as general, life cycle, technical, relation, and classification categories, are considered as the must-be requirement, and with these categories, the requirement of modifying element names is applied. That is, for example, we suggest that identifier element in the general category is modified as the 'General Identifier', and identifier element in the relation category is modified as the 'Relation Identifier'. Name element in the technical category is changed as the 'Operating Systems Name' and 'Browser Name’.

Table 2. Model of Metadata Design

\begin{tabular}{|c|c|c|c|c|}
\hline & $\begin{array}{l}\text { Former KEM } 3.0 \\
\text { Category }\end{array}$ & $\begin{array}{l}\text { E-learning Metadata } \\
\text { Requirement }\end{array}$ & $\begin{array}{l}\text { IT environment } \\
\text { Requirement }\end{array}$ & $\begin{array}{c}\text { Education environment } \\
\text { requirement }\end{array}$ \\
\hline $\begin{array}{l}\text { L1 } \\
\text { Must-be } \\
\text { Requirements }\end{array}$ & $\begin{array}{l}\text { - General } \\
\text { - Life Cycle } \\
\text { - Technical } \\
\text { - Relation } \\
\text { - Classification }\end{array}$ & $\begin{array}{l}\text { - Changing the name of } \\
\text { some element 'Identifier' in } \\
\text { General and Relation } \\
\text { category, 'Contribute' in Life } \\
\text { Cycle category, and the name } \\
\text { of element 'name' in } \\
\text { Technical category in order } \\
\text { to prevent the use of } \\
\text { overlapping }\end{array}$ & - & - \\
\hline $\begin{array}{l}\text { L2 } \\
\text { One- } \\
\text { dimensional } \\
\text { Requirements }\end{array}$ & $\begin{array}{l}\text { - Meta-metadata } \\
\text { - Educational } \\
\text { - Rights }\end{array}$ & $\begin{array}{l}\text { - Changing the name of } \\
\text { element 'Identifier' in } \\
\text { Technical category } \\
\text { - Dividing the element } \\
\text { 'Interactivity level', } \\
\text { 'Semantic Density', and } \\
\text { 'Difficulty' in Educational } \\
\text { category }\end{array}$ & $\begin{array}{l}\text { - Applying CCL } \\
\text { requirements in } \\
\text { rights category }\end{array}$ & $\begin{array}{l}\text { - Applying brand new } \\
\text { pedagogical methods (R- } \\
\text { learning, T-learning) in } \\
\text { educational category }\end{array}$ \\
\hline $\begin{array}{l}\text { L3 } \\
\text { Attractive } \\
\text { Requirements }\end{array}$ & - Annotation & - & $\begin{array}{l}\text { - Creating Media } \\
\text { category }\end{array}$ & $\begin{array}{l}\text { - Applying social media } \\
\text { elements }\end{array}$ \\
\hline
\end{tabular}


Volume XII, No. 2, pp. 74-79, 2011

Followed by Figure 1, three categories, such as Meta-metadata, educational, rights categories, are classified as onedimensional requirements, and with these categories, the requirement of modifying element names is applied. For instance, we suggest that the identifier element in the meta-metadata category is modified as the 'Meta-metadata Identifier', and the contribute element in the same category is modified as the 'Meta-metadata Contribute'. In addition, under the interactivity level element in the education category, we set two sub-elements such as 'Providers' Interactivity Level' and 'Learners' Interactivity Level' to make an evaluation provided by both providers and learners. As the same way, the semantic density element and the difficulty element can be considered both providers' and learners' opinion with separated elements. Moreover, considering the environmental changes of copyrights, CCL elements will be included under the rights category. Under the educational category, new pedagogical methods like R-learning and Tlearning can be input in the interactivity type element.

Based on the classification of the metadata importance, we classify the annotation category as the attractive requirements. Then, the media category will be emerged in order to apply the requirement about social network services or new media like IPTV and Tablet PC.

In short, we deduce e-Learning metadata requirements from three-level layers, such as must-be, one-dimensional, and attractive requirements. These requirements are based on three environments surrounded in e-Learning: KEM 3.0 metadata requirements, IT environment requirements, and education environment requirement. Table 2 shows the relationship between three-level layers and environment requirements in order to design the requirements of e-Learning metadata.

\section{CONCLUSIONS}

In this paper, we analyze existing e-Learning metadata model, and finding requirements for designing new intelligent tutoring system. Then, we design new e-Learning metadata based on KEM 3.0, Korean e-Learning contents standard. Nowadays, the intelligent tutoring system has been evolved from expanding learners' participation, changing the multidevice environment, and emerging social network and collective intelligence, and this research applied these changes into the e-Learning metadata design. In this research, using Kano Model, we classify requirements for re-designing metadata, and then research new e-Learning metadata structure interoperating with the KEM standard. The result of this research is providing e-Learning systems which can adopt in any IT environment, and cultivating new services. This research has some contributions compared with existed e-Learning metadata researches. First, this research can apply eLearning operated with multi-devices such as IPTV and smart phones. Some elements in the metadata category which are suggested in this paper include the specification of multi-devices. Second, this research can contribute in the eLearning environment considered with copyright environment in order to activate various users' participation. Last, this research makes it possible to re-design e-Learning metadata effectively with considering the frequency of using metadata.

The next step of the research will be developing the intelligent tutoring system based on the design structure that suggests in this paper with international standards, and designing the real world services with this research. Moreover, the measure of study effects with this model will be needed.

\section{ACKNOWLEDGMENT}

This work was supported by the Korean Government IT R\&D program of MKE/KEIT. [10035166, Development of Intelligent Tutoring System for Nursing Creative HR]

\section{REFERENCES}

1. D. Brickley, S. Buswell, B. Matthews, L. Miller, D. Reynolds, M. Wilson (2002). SWAD-Europe: Semantic Web Advanced Development in Europe. Presented at the 1st International Semantic Web Conference.

2. Stutt, E. Motta (2004). Semantic Webs for Learning: A Vision and Its Realization. Proc. of EKAW 2004, LNCS 
Volume XII, No. 2, pp. 74-79, 2011

3257. Springer-Verlag, pp.132-143.

3. Laura Gordon-Murnane(2006). Social Book-marking, Folksonomies, and Web 2.0 Tools. Searcher, Vol.14, Iss.6, pp.26-39.

4. Josh B. (2009), Social technology growth marches on in 2009, led by social network sites, http://forrester.typepad.com/

5. Nycz, M. \& Smok, B. (2003). Distance education as a way to meet the challenges of the XXI Century. Proceedings of the SympoTIC'03 Joint 1st Workshop on Mobile Future \& Symposium on Trends in Communications (pp. 2628), IEEE CS Section, Bratislava, Slovakia.

6. R. Junco, G. Heibergert \& E. Loken (2010), The effect of Twitter on college student engagement and grades, Journal of Computer assisted learning, Volume 26, Issue 5, pp.1-14

7. N. Manouselis, R. Vuorikari \& F. Van Assche (2010), Collaborative Recommendation of e-learning resources: an experimental investigation, Journal of Computer assisted learning, Volume 26, Issue 5, pp. 227-242

8. Duval E. (2001), Metadata Standards: What, Who and Why, Journal of universal computer science, vol 7, no 7, pp.591-601

9. N. Friesen (2005), Interoperability and Learning Objects: An Overview of E-Learning Standardization, Interdisciplinary Journal of Knowledge and Learning Objects, Volume 1, pp. 23-31

10. X. Liu, A. El Saddik \& N.D. Georganas (2003), An implementable architecture of an e-learning system, Canadian Conference on Electrical and Computer Engineering

11. Y. Ahn \& O. Park (2009), A Study on the Metadata Elements for Establishing e-Learning Content Archives, Journal of Korean Library Information Society, Vol. 43, No. 3, pp. 147-162

12. Y. Choi \& Y. Chung (2008), A Study on Metadata Elements for Digital Course Resources in Universities, Research of Information Management, Vol. 39, No. 3, pp. 23-48

13. Creative Commons Korea, http://www.cckorea.org

14. Kay C. Tan \& Theresia A. Pawitra (2001), Integrating SERVQUAL and Kano's model into QFD for service excellence development, Managing Service Quality, Volume 11, Issue 6, pp.418-430.

15. Nilsson, M., Palmer, M., Naeve, A (2002). Semantic Web Meta-data for e-Learning - Some Architectural Guidelines, Proceedings of the 11th World Wide Web Conference(WWW2002), Hawaii, USA:http://kmr.nada.kth.se/papers/SemanticWeb/p744-nilsson.pdf 